\title{
LA ESTÉTICA DE KANT: EL ARTE EN EL ÁMBITO DE LO PÚBLICO
}

\author{
Kathia Hanza \\ Pontificia Universidad Católica del Perú \\ khanza@pucp.edu.pe
}

\begin{abstract}
Resumen
El artículo busca valorar el papel que tiene la teoría estética de Kant con relación al arte. A manera de introducción se ubica a Kant en el contexto de su época: en el espíritu y sensibilidad que comparte con sus contemporáneos. Aunque esta sujeción pueda alejar a su teoría de la manera como actualmente apreciamos el arte, lo importante es reparar en el núcleo de su propuesta: la autonomía de lo estético, con lo que Kant asume una posición radicalmente distinta a las que lo precedieron. Esta autonomía es luego revisada en el presente estudio a la luz de la intersubjetividad. Se trata de mostrar cómo la teoría kantiana de lo estético, centrada en ofrecer una solución a la cuestión de la legitimidad de los juicios estéticos, reafirma, vía la intersubjetividad puesta de manifiesto en juicios estéticos y obras de arte, el espacio público del arte.
\end{abstract}

Palabras clave: Kant, juicio estético, arte, intersubjetividad, espacio público.

\begin{abstract}
We seek to assess the role that Kant's aesthetic theory can play in connection with art. We begin by placing Kant in the context of his time: the spirit and sensibility he shares with his contemporaries. Although this conditioning may detach his theory from the way we now appreciate art, one should above all pay attention to the gist of his proposal: by asserting the autonomy of the aesthetical Kant takes a stance which is radically different from that of his predecessors. We examine this autonomy in the light of intersubjectivity and try to show that the Kantian theory of the aesthetical, which aims to give a solution to the question of the legitimacy of aesthetic judgments, reaffirms-through the intersubjectivity manifested in aesthetic judgments and works of art- the public space of art.
\end{abstract}

KeYwords: Kant, aesthetic judgment, art, intersubjectivity, public space.

$\overline{R A}$

Hay ciertas cosas que parecieran pertenecer ni más ni menos que al pasado. Una de ellas, sostienen muchos, es la estética de Kant. Esta apreciación se explica, en gran parte, por la sorpresa y extrañeza que suscita la lectura de la Crítica de la facultad de juzgar a los lectores modernos. Acostumbrados, como estamos, a las estéticas contemporáneas que centran su atención en el arte, la kantiana gira en torno a una belleza que concierne más a los productos de la naturaleza que del arte. Casi de 
manera tangencial y esquiva dedica Kant unos pocos parágrafos de su obra a la belleza artística. Y, por si fuera poco, la misma noción de belleza, tan cara a Kant, a su siglo y a las teorías clásicas sobre el arte, nos despierta la sospecha de corresponder, a la luz del arte que hoy se hace, a una sensibilidad obsoleta (cf. Perniola 2001, p. 196). Si, además, reparamos en uno de los términos clave de la estética de Kant, el "gusto", que ahora lo asumimos como completamente desfasado y elitista o, en todo caso, idiosincrásico, propio de círculos anticuados, insustanciales o particulares, tendríamos que concluir que será muy poco lo que encontremos en su obra que nos sirva para esclarecer lo que el arte hoy nos demanda ${ }^{1}$.

El propio siglo de Kant, llamado con razón, a la vez, el siglo de la estética y el siglo de las luces, no correría mejor suerte. ¿Qué impresión sino la de la lejanía y extrañeza podría causarnos esa profusión tan particular de cuestiones estéticas? Por mera curiosidad intelectual y no con la intención de comprender qué es el arte hoy, tendría caso conocer los peculiares rasgos que dicho siglo exhibe. Allí encontramos una reverberación de problemas estéticos, que podríamos tratar como curiosidades de una época remota. Así, la crítica del gusto, ejercida por tantos autores ingleses, franceses, alemanes, el horizonte poético con el que se considera a las artes, el esquema gnoseológico de Baumgarten, las investigaciones de Vico, las reflexiones de los artistas, los críticos y los poetas, junto con los problemas planteados en torno a los límites de la percepción, las cuestiones relativas al placer, a la belleza, al sentimiento, a la forma, las características que tantos autores se empeñaron en advertir en las artes ${ }^{2}$, el reverente temor ante la inmensa grandeza de la naturaleza, constituirían nada más el telón de fondo, distante y ajeno, en el cual situaríamos la vieja empresa de Kant (cf. Franzini 2000, p. 15). Una empresa barroca en el portentoso galeón de un viaje que llevó a ese siglo desde las metafísicas de la belleza a la relatividad del gusto.

El viaje no es, en el siglo de Kant, una simple metáfora. Se conocen nuevos horizontes en los que pueden confrontarse diversas experiencias y visiones del mundo. Justamente la exaltación descriptiva de la variedad y la diferencia, para la cual el problema del gusto, clave para ese siglo, es harto significativo, unida a la amplitud cualitativa y cuantitativa, sin precedentes hasta ese momento, van acompañadas del hecho de que las ideas se transmiten con relativa velocidad; a los descubrimientos geográficos siguen exploraciones, "el viaje mismo es entendido como una dimensión

1 A estas dificultades se añaden otras. Así, por ejemplo, Danto sostiene que: "Kant was through and through architectonic, and one must see where beauty, and only incidentally art, fits in the whole grand design of his system" (Danto 2000, p. xiv). De hecho, Danto sostiene que hay poco que aprender de Kant en material de arte, por eso, concluye: "And the truth is that philosophers as well as artists may have a great deal more to learn from the philosophers after Kant, than from Kant himself" (ibíd.).

2 Jean-Marie Schaeffer ofrece cifras muy significativas con respecto a la edición de libros, que dan cuenta de la amplitud cuantitativa y cualitativa de dicho siglo: entre 1600 y 1700 , unos 250.000 libros fueron publicados en Europa: esa cifra se convierte en cerca de 2 millones entre 1700 y 1800 (cf. Schaeffer 2000, p. 121). 
viviente del pensamiento" (Franzini 2000, p. 52). Pero Kant, como sabemos, pese a sus ínfulas cosmopolitas, solo conoce Königsberg. No es un filósofo errante, lo que no significa, sin embargo, que su pensamiento sea gregario. Ocurre, más bien, que emprende la tarea de ordenar de forma crítica la increíble profusión de cuestiones estéticas planteadas a lo largo de ese siglo $\mathrm{XVIII}^{3}$.

Vale la pena reparar en que la empresa de ordenar y a la vez mostrar los principios que animan los distintos planteamientos estéticos de su época se lleva a cabo en una obra cuyo título es Crítica de la facultad de juzgar. Aquello que a nuestros ojos despierta la impresión de extrañeza y lejanía, a saber, que Kant trate los problemas de la estética en una obra dedicada a la manera cómo juzgamos, a las pretensiones que ostentamos en nuestros juicios y en cómo resolverlas, debiera, pues, mirarse con más cuidado. Por ese camino de la crítica, esto es, del deslinde, del análisis y la ponderación de los supuestos implicados, encontrará la forma de presentar, de una manera sistemática, los argumentos y consideraciones estéticas de sus contemporáneos que, por lo demás, se dibujan en ciertas preferencias nacionales. Así, en Inglaterra predomina la determinación del gusto sobre bases empiristas o psicológicas, en Italia dominan las tradiciones poético-retóricas, en Alemania destaca la exigencia cognoscitiva y en Francia, cuándo no, los autores disputan acalorada y apasionadamente sobre una cuestión en particular: si es mejor el arte de los antiguos o el de los modernos (cf. Franzini 2000, p. 12). A su manera, entonces, sin salir de la apacible Königsberg, viaja Kant por estas distintas corrientes y exploraciones estéticas.

En los cuatro momentos de la Analítica de facultad estética, sin citar prácticamente a sus contemporáneos ${ }^{4}$, Kant consigue ordenar y zanjar las diferencias y preferencias de enfoques entre dichas corrientes. Básicamente, y pese a las simplificaciones en las que incurro, se delinea un debate con empiristas y racionalistas. Contra los empiristas, Kant sostendrá que el juicio de gusto no es explicable por argumentos sensualistas; contra los racionalistas, deslindará que en él no están en juego elementos cognitivos o conceptuales. Más allá de estos claros rasgos demarcatorios, Kant comparte con su época una cierta inseguridad originaria entre la doctrina de la sensibilidad y las teorías sobre el arte. Se trata de una oscilación que sigue despertando nuestro interés; piénsese, por ejemplo, en la fenomenología del arte desde Merleau-Ponty en adelante, y el lugar que allí tiene la percepción. Ahora bien, en el seno de aquel

3 No quisiera dar a entender que deben leerse a los autores del siglo XVIII simplemente como un telón de fondo de la empresa kantiana. Tampoco, que ellos merezcan nada más que nuestra curiosidad histórico-filológica. De hecho, la preeminencia de Kant ha opacado, por ejemplo, el estudio de lo que la Estética de Baumgarten (a quien le debemos la acuñación moderna del término) ha significado en nuestra comprensión del arte y de las manifestaciones estéticas. En castellano, contamos con algunos textos de Baumgarten, Wickelmann, Mendelssohn y Hamann reunidos por Mateu Cabot (1999). También la investigación de Alfred Baeumler (1981), publicada por primera vez en 1923, constituye una fuente obligada para conocer las discusiones estéticas de dicho siglo.

4 Entre sus contemporáneos, Kant menciona a Batteaux, Burke, Hume, Lessing, Locke, Newton, Voltaire y Wieland. 
debate Kant marca una distancia inequívoca con respecto a su propia época, al proponer que los juicios de gusto son autónomos, es decir, distintos a los juicios de conocimiento o morales. Pero, además, con argumentos distintos a los de sus contemporáneos destacará que la experiencia estética es intersubjetiva, esto es, concierne a todos los que juzgamos y hacemos arte. El propósito principal de la Crítica de la facultad de juzgar estética -sustentar en qué pueda basarse la legitimidad de nuestros juicios estéticos-se sostiene en la raíz intersubjetiva de nuestras prácticas estéticas.

A todas luces vemos que la primera propuesta de Kant, la autonomía de lo estético, es afín a nuestra experiencia. No se trata solamente de que difícilmente podremos equiparar, sin borronear toscamente las diferencias, lo que ocurre cuando conocemos un hecho del mundo, calificamos ética o moralmente nuestras acciones, o apreciamos los rasgos estéticos de ciertos objetos. El punto central es, más bien, que no sustentamos la pertinencia de las manifestaciones estéticas por razones morales o de conocimiento: no decimos que un objeto sea estéticamente significativo porque nos haga conocer aspectos de la realidad o porque se ajuste a nuestras valoraciones éticas. Bajo esos estrictos criterios restrictivos tendríamos que tomar como serias desviaciones casi todo el arte desde el impresionismo en adelante y, bien miradas las cosas, no poco arte del pasado. Concedo que algunos preferirían borrar de un plumazo todo el escándalo que anima buena parte de nuestro arte contemporáneo. Ante los ready-made de Duchamp, el Cuadrado negro de Malevitch ${ }^{5}$, las entre tanto famosísimas Brillo Box de Warhol, el Teatro del Misterio de las Orgías de Hermann Nitsch, algunas fotografías de Robert Mapplethorpe o de Joel Peter Witkin, las Corrections que hace Rassim Krastev en su propio cuerpo ${ }^{6}$, las instalaciones, los performances, el arte conceptual, mediático, minimalista, etc. -y hay innumerables etc.- muchos se preguntan, no sin razón, pero ¿esto es arte?, como lo hace Cynthia Freeland en el título de su libro (Freeland 2003). Adviértase que, más allá de consideraciones morales o cognitivas, estamos preguntándonos si todavía pueden ciertas manifestaciones ser comprendidas como arte ya que, ante otras, pese al rechazo moral que puedan suscitarnos o su nula contribución al conocimiento, sí estamos dispuestos a tomarlas como tal. Quizá aquel deseo de borrar de un plumazo tantas "obras" ética o cognoscitivamente equívocas se deba simplemente a un anhelo muy básico de que las cosas sean distintas a lo que son, más que a una reacción meditada y sustentada. Así pues, la autonomía de lo estético es hoy por hoy algo que, incluso ante situaciones límite, todos comúnmente aceptamos. Podría incluso aventurarme a lanzar como hipótesis que tales situaciones límite, de las que hace gala el arte contemporáneo, bien podrían ser exploraciones extremas de algo que básicamente ya todos admitimos: la autonomía de lo estético.

5 1916.

6 Por ejemplo, en la Bienal de Sao Paulo del 2004 presentó Corrections 2, un video con imágenes de su circuncisión. 
Detengámonos un momento en la intersubjetividad de la experiencia estética. Como sabemos, Kant realiza un análisis de lo que afirmamos cuando decimos que algo es, en sus términos, bello. El análisis presenta las bases para concluir que con dicho juicio estético apelamos a un "sentido común", esto es, a unas mismas capacidades para juzgar la manera como a todos nos podría afectar subjetivamente una representación ${ }^{7}$. Eso significa que, basándonos en esa misma capacidad para reaccionar estéticamente, afirmamos que todos podríamos tener, en cierto sentido, la misma experiencia de placer o displacer. Apelamos en suma, en los términos de Kant, a una universalidad subjetiva (cf. Kant 1991, p. 130, § 8). Esta universalidad subjetiva concierne principalmente a la intersubjetividad. Es decir, Kant intenta mostrar que hay algo en nuestra experiencia humana que, aunque no pueda ser objetivable, es accesible intersubjetivamente (cf. Früchtl 1994, p. 54). A qué me refiero exactamente y por qué este rasgo tiene plena actualidad serán tratados más adelante. Por el momento baste indicar que, aunque este segundo rasgo no pasa desapercibido, pocas veces se le presta la atención debida. Normalmente, se asume que la estética de Kant, antes que apelar a un modo común de reaccionar estéticamente, sirve más bien para hacer prevalecer el juicio subjetivo ${ }^{8}$. Tal confusión se explica por el rasgo que señalé primero: si los juicios estéticos son autónomos y, en este caso, no solo ajenos a razones cognitivas o morales, sino también autónomos en el sentido de que no debemos guiarnos por la manera cómo los demás juzgan, sino, más bien, que deba ser cada uno de nosotros quien con independencia juzgue, se corre el riesgo de interpretar este sentido de la autonomía como la pretensión de asumir que el juicio de cada uno será lo que prevalezca. Es decir, podría ocurrir que nuestras simples preferencias subjetivas, idiosincrásicas y privadas inclinasen la propia apreciación estética de cada uno de nosotros. Para evitar tal confusión, será preciso tener en cuenta que Kant no solo aboga por la autonomía, sino también por la intersubjetividad. Es más, propiamente hablando, para Kant será posible la autonomía únicamente si ella se sustenta en la intersubjetividad, esto es, en el "sentido común". Será preciso, pues, desarrollar en un primer momento los vínculos entre intersubjetividad y autonomía.

En un segundo momento quisiera ocuparme de la actualidad de la intersubjetividad bajo el aspecto de la creación artística. Como veremos, el supuesto de un sentido "común" en su relación con el arte aporta a los debates actuales, al proponernos que en materia de estética es irrenunciable una misma manera de reaccionar sustentada en la intersubjetividad.

Me remito a los parágrafos 1, 20,38 de la Crítica de la facultad de juzgar.

Por ejemplo, el influyente crítico norteamericano Greenberg, sostuvo: "La calidad en arte no puede ser ni investigada ni aprobada por la lógica o el discurso. Sólo la experiencia gobierna en esta área -y la experiencia, por así decir, de la experiencia. Esto es lo que concluyeron todos los filósofos serios del arte desde Immanuel Kant”. Citado por Arthur C. Danto (1999, p. 102). 


\section{Intersubjetividad y autonomía estética}

Comencemos con la precisión que hace Kant a propósito del término "estética". La encontramos al inicio de la Crítica de la facultad de juzgar. "Estético" se refiere simplemente a cómo "el sujeto se siente a sí mismo tal como es afectado por una representación" (Kant 1991, p 121, § 1). Sugiero entender la palabra "representación" en su sentido más básico y amplio: cualquier cosa de la que tomemos noticia, de la que nos percatemos: un sonido, un color y, por supuesto, configuraciones más complejas como un cristal de cuarzo o una obra de arte. Ahora bien, lo importante, para Kant, es cómo, en un sentido estético, esa representación nos afecta, cómo nos sentimos a propósito de ella, es decir, el polo meramente subjetivo de la representación y no su polo objetivo, vale decir, a qué ella refiera. Esto es esencial: lo estético es únicamente lo que sentimos a propósito de cualquier representación y no consiste en determinadas cualidades objetivas de los objetos. Ciertamente, esas cualidades objetivas incidirán en la representación y cómo uno se pueda sentir a propósito de ella, pero, insiste Kant, sería equívoco llamarlas estéticas. Kant entiende por estético algo muy preciso y que es necesario no perder jamás de vista para seguir la lógica de su argumentación. Estético es un sentimiento específico que nos suscita cualquier representación, sin que importen sus orígenes objetivos. Por supuesto que, además, toda representación se refiere a algo, pero eso no es lo determinante para calificarla como estética. Si se tiene un sentimiento tal que pueda esperarse -Kant va incluso más allá y dice: que pueda exigirse (cf. Kant 1991, p. 129, § 7)- que todo sujeto lo tenga, es decir, que todo sujeto, ante tal representación, pueda reaccionar de esa manera, entonces el sentimiento será estético. No todas nuestras reacciones subjetivas son de este tipo, por ejemplo, el agrado que siento con el sabor de la lúcuma, no es algo que pueda atribuirle a cualquiera, ni mucho menos exigirlo. Concedo que a algunos les gustará ese sabor, pero a otros no. Y acepto, en casos como éste, sin mayores dificultades, preferencias privadas, idiosincrásicas con respecto a lo que nos agrada y lo que no. Si, en cambio, estoy parada frente a la Iglesia de la Compañía en el Cusco y todo el fuego del sol que cae por la tarde ilumina y hace resaltar sus formas, como si esa fachada fuese ella misma uno de los maravillosos altares que están en su interior, y todo ese esplendor aparece recortado todavía bajo un cielo azul intenso, diré que esa imagen es bella. En este caso, también tendré una reacción subjetiva -la "representación" me afecta de determinada manera-, pero difícilmente podré aceptar que cualquiera que vea lo que yo veo no lo encontrará bello, que cualquiera no pueda tener esa misma reacción estética. No tengo ninguna garantía de que eso ocurra, porque se trata de una reacción subjetiva, librada a una cierta espontaneidad y gratuidad, pero mi sentimiento es de tal calidad, que podría esperar que todos reaccionásemos igual, podría pedir el asentimiento de todos, independientemente de si a algunos les agradan más las iglesias barrocas que, digamos, los edificios postmodernos. Es importante insistir en este punto, crucial para Kant: cuando se dice que algo es "bello", primero, no se está calificando un determinado objeto sino que se está expresando un sentimiento, y, segundo, que ese sentimiento es de tal naturaleza que no puede confundirse con una mera reacción privada, exclusiva de una persona en particular o de un determinado grupo, al que le agradan ciertas cosas y no otras. 
Cuando Kant establece de esta forma qué es lo "estético" está poniendo en cuestión una importante gama de planteamientos sobre el gusto y la belleza. Está sosteniendo, en primer lugar, que se equivocan quienes piensan que la belleza se explica fundamentalmente por las cualidades objetivas de las cosas, como es el caso de los que sostienen que la belleza es "perfección sensible". Aquí, el espectro de autores es muy amplio y podría uno remontarse al viejo Platón, pero también traer a colación a los racionalistas contemporáneos de Kant, a Baumgarten, por ejemplo. Pero está discutiendo también, en segundo lugar, la opinión, expresada por la escuela empirista de que el "fundamento del gusto es la experiencia" (Hume 2003, p. 42) y que el gusto tiene principios que son "uniformes en la naturaleza humana" (Hume 2003, p. 65). En pocos pasos, aunque reparando en más detalles que los que yo he expuesto, Kant plantea la cuestión de la "estética" desde una perspectiva no considerada por la tradición, a la vez que muestra las debilidades de los planteamientos de sus contemporáneos y los ubica en torno a un eje conceptual que puede explicar muchas cosas que los otros no están en condiciones de ofrecer. Así, si la belleza fuese perfección, esto es, algo objetivo, ¿cómo explicar que, por ejemplo, una simple esfera nos es algo indiferente o que la plena funcionalidad del edificio de departamentos construido por Mies van der Rohde en Chicago haya sido hasta tal punto intolerable que se optó por destruirlo? ¿Por qué la perfecta reproducción de una persona en una escultura tendría que ser bella? Los límites entre la perfección, lo obvio, lo estrictamente regular, la mera reproducción, etc., son borrosos. Y, por otro lado, si el gusto dependiese de condicionamientos subjetivos, culturales o históricos, ¿cómo explicar que encontramos bella una cerámica Nasca o ciertos arrecifes coralinos? ¿Acaso compartimos la misma psique o cultura de ese artista desconocido? ¿Dónde está la historia y la cultura con respecto a los arrecifes? La increíble vigencia de Kant radica en el hecho de que con muy pocos elementos puede explicar fenómenos muy diversos. Y lo menos que podemos pedir de una explicación es que no deba hacer demasiadas peripecias para abarcar la mayor cantidad de problemas.

$\mathrm{Al}$ analizar los juicios sobre la belleza -o, lo que es lo mismo, los juicios de gusto- Kant advierte otras características importantes ${ }^{9}$. Se trata de un análisis cuidadoso y meticuloso que no tendría caso exponer aquí. Pero sí es fundamental advertir uno de los rasgos principales de los juicios estéticos. Hemos visto que el sentimiento estético, que Kant no duda en calificar como "placer" (Wohlgefallen), es de tal naturaleza que no podríamos confundirlo con el agrado, pues éste supone una mera preferencia privada o personal. Así, cuando se afirma que "x es bello" se está diciendo algo cualitativamente diferente a cuando se sostiene que "y me agrada". En el primer caso, solicitamos que todos concuerden con ese juicio, en el segundo, no buscamos en absoluto que todos coincidan. Estamos frente a una característica especial de los juicios

9 Se trata de un análisis cuyos momentos esenciales son: desde el punto de vista de la calidad, el placer es desinteresado; desde la cantidad, es universalmente subjetivo, desde la relación, es conforme a fin sin fin; desde la modalidad, es necesariamente subjetivo bajo el supuesto de un "sentido común" estético. 
en los que atribuimos belleza: plantean ser universales, esto es, que todos los que juzguen concuerden. Pero ocurre que, por definición, tales juicios son estéticos, es decir, informan a lo sumo sobre una reacción subjetiva a propósito de una representación. ¿Cómo podría un juicio subjetivo ser universal? O, lo que también se desprende de lo anterior, ¿cómo podría un sentimiento comunicarse universalmente? (cf. Kant 1991, p. 135, § 9).

Tomemos en cuenta que los juicios objetivos son, por derecho, universales. Si digo: "el cuadrado es una figura de cuatro lados" o "este papel es blanco", no cabe que alguien diga: "a mí no me parece". Si así fuese, en el mejor de los casos pensaríamos que no sabe qué significan esas palabras, en el peor-y más plausible-dudaríamos de si está en su sano juicio. Los juicios en los que decimos "x es bello" (o, para el caso, también su contrario, "x es feo") tienen la misma forma lógica que los juicios objetivos. Es decir, que pareciera que estuviéramos atribuyendo el predicado de "belleza" a $\mathrm{x}$, como cuando le atribuimos el predicado "blanco" a un papel. Kant nos explica que, en realidad, no es así, pues con el predicado "bello" no estamos calificando objetivamente algo, sino informando cómo subjetivamente nos afecta. "Bello" no es, pues, un concepto que atribuyamos a las cosas simplemente por sus cualidades objetivas, sino un sentimiento que esperamos se suscite también en los demás. Lo notable y lo que exige una explicación es con qué derecho asumimos que podríamos atribuir a todos ese sentimiento, esa misma reacción estética.

Revisemos con más detalle esta cuestión. Lo que Kant sostiene es que, de hecho, al enunciar juicios estéticos, no estamos juzgando en virtud de determinadas características (conceptos o cualidades objetivas) de las cosas que podamos conocer, como tampoco lo estamos haciendo por meras preferencias personales, del tipo "me gusta". Lo que ocurre, más bien, es que estamos planteando una exigencia muy especial: juzgar por el sentimiento de una forma que podamos atribuir a todos. Esto es, sin conceptos y de manera subjetiva; subjetiva, aunque no privada, sino universal. Intentamos pues algo sumamente sorprendente: comunicarnos universalmente vía el sentimiento. Kant plantea que esto es algo que, de hecho, hacemos, y busca dar una respuesta a la pregunta de con qué derecho lo hacemos.

Su respuesta es que solo admitiendo un "sentido común", una misma capacidad en los seres humanos para reaccionar estéticamente, puede resolverse ese enigma, puede explicarse coherentemente esa pretensión que, de hecho, tenemos.

Con "sentido común" estético no tiene en mente Kant una oscura y abstrusa capacidad innata que tuviésemos las personas, a la manera de algo propio de nuestra naturaleza humana, tampoco en una aptitud alcanzada por la experiencia. Piensa, más bien, que dicho "sentido común" estético consiste en las mismas facultades que demostramos poseer al conocer, y que son la "imaginación" y el "entendimiento", pero que justamente no las empleamos con el propósito de conocer, sino de forma espontánea, en un juego armónico y libre (cf. Kant 2001, p. 143, § 9). Ellas simplemente operan, en el caso de lo estético, de forma distinta a como ocurre cuando conocemos. Consiguen que tomemos conciencia de un estado que podríamos atribuir a todos, porque todos contamos con las mismas facultades. No se necesita, pues, dotarnos de un 
"nuevo sentido", de una especial sensibilidad o capacidad, de algunas dotes sutiles y refinadas para resolver las dificultades conceptuales, filosóficas, unidas a los juicios de gusto. Su respuesta es, a la larga, simple; si reaccionamos estéticamente es porque lo hacemos de forma subjetiva, y si atribuimos esa misma reacción a los demás es porque poseemos las mismas capacidades que los demás ${ }^{10}$.

Por supuesto que el hecho de que alguno de nosotros experimente la belleza de un poema, de una pieza de música o de un grabado no es en absoluto una garantía de que todos sientan lo mismo. Como tampoco es válida la situación contraria: que muchos consideren una película excelente o abominable tampoco debiera necesariamente inclinarnos a apreciarla de esa misma manera. No es la intención de Kant uniformizar nuestros juicios, ni mucho menos establecer un canon de lo que legítimamente debería valer como una genuina reacción estética. Nos equivocaríamos rotundamente si buscásemos interpretar su planteamiento así. Es importante señalar que, para él, la experiencia estética es autónoma en el sentido de que somos cada uno de nosotros quienes juzgamos y, por ende, solo cada uno de nosotros podrá reconocer la especificidad de su reacción estética. Es en cada uno de nosotros donde se presenta esa forma de reaccionar subjetiva que Kant llama "sentimiento", de manera que, si bien los demás podrían argüir razones y exponer sus puntos de vista para tratar de que otros reaccionasen como ellos, en la medida en que el núcleo de la experiencia estética es un sentimiento, ningún argumento podría llevarlos a sentir de una determinada manera. Y, sin embargo, como veíamos, la experiencia estética es también de tal naturaleza que en la reacción debe tomarse en cuenta a "cada uno de los demás" (Kant 2001, p. 204, § 40), pues de otra forma sería meramente privada. Esto resulta esencial: es cada uno quien debe juzgar, pero ateniéndose de alguna forma a que los demás también puedan juzgar así. Atendiendo a este rasgo es que podemos afirmar que el juicio estético es intersubjetivo y que existe una dimensión no objetivable de nuestra experiencia que, sin embargo, legítimamente podríamos compartir con otros. En tal sentido, la experiencia estética es pública, plural, concierne a todos.

\section{Intersubjetividad y arte}

Es momento de situar bajo esta perspectiva de lo público, aunque no objetivable, al arte. Podrá parecer extraño poner las cosas de esa manera, pues justamente las obras de arte están allí, son objetos entre otros en el mundo. Pero ¿acaso es cierto que sean objetos como las mesas o los árboles? Aquí nos encontramos con una variante de una pregunta formulada anteriormente. Ante ciertas obras de arte moderno, muchos

10 He obviado algunos rasgos importantes del "sentido común", por ejemplo, su diferencia con nuestros sentidos orgánicos o el vínculo entre experiencia del mundo y experiencia de sí. Una breve y sugerente referencia a estos puntos puede encontrarse en la Introducción de Eliane Escoubas a su libro L'Esthétique (Escoubas 2004, pp. 7 ss.). 
espectadores nos preguntamos si son arte. ¿Qué hace que un objeto sea una obra de arte? Esta es una pregunta esencial para uno de los estudiosos actuales del arte. Arthur C. Danto ha perseguido infatigablemente esta pregunta y ha elaborado una sugerente respuesta al tomar como momentos fundamentales en el desarrollo del concepto moderno de arte las populares Brillo Boxes de Andy Warhol y la Fuente de Duchamp (cf. Danto 1999, p. 138). Es decir, dos obras que por sus propiedades observables no pueden ser distinguidas de otros simples objetos del mundo cotidiano. Lo que hace de aquellas piezas obras de arte, propone Danto, no son determinadas cualidades objetivas, sino dos condiciones básicas, aplicables a todo arte: 1) ser acerca de algo y 2) encarnar un sentido (cf. Danto 1999, p. 204). Es decir, podríamos nosotros concluir, condiciones que solo como sujetos podríamos advertir ${ }^{11}$.

Al comienzo advertimos que las cuestiones que el arte moderno plantea y, más directamente, las condiciones para tomar una obra como arte parecen estar, a primera vista, muy lejos del universo de problemas de los que Kant se ocupa. Sin embargo, la coincidencia sobre los rasgos no objetivables del arte entre Kant y, por ejemplo, Danto, pueden ayudar a mostrar que esa impresión inicial no es acertada. Antes será preciso especificar el lugar que la teoría sobre el arte tiene en la estética de Kant.

Este punto acarrea una dificultad particular. Kant se ocupa del arte apenas en unos pocos parágrafos de la Crítica de la facultad de juzgar. Centrada en el análisis y legitimación del juicio de gusto, la argumentación tiene como, observa Lyotard, ciertas “torsiones lógicas" (Lyotard 1988, p. 67) sorprendentes, pero uno no puede menos que concluir, con Kant, que los estrictos parámetros impuestos a los juicios para ser legítimos se ajustan exclusivamente a los que conciernen a la belleza natural. En efecto, reducido el rol de los conceptos a su mínima expresión, el arte parece estar contemplado, en el texto de Kant, bajo una política de excepciones o en la búsqueda del restablecimiento de un equilibrio entre la belleza artística y la natural o, incluso, en la propuesta de una identidad entre ambas (cf. Prego 1990, pp. 132 ss.) ${ }^{12}$. Los pasajes dedicados al arte suscitan la impresión de ser una suerte de parerga (cf. Allison 2001,

11 Esta no es una conclusión que Danto extraiga de su planteamiento. Por el contrario, su búsqueda es "esencialista", esto es, intenta ofrecer una definición del arte que ahuyente las confusiones o imprecisiones subjetivistas que, asume, son propias de Kant (cf. Danto 2002, pp.58, 96 ss.).

Es correcto afirmar que Kant propugna la identidad entre belleza natural y belleza artística, que, además, será fundamental para la posterior teoría romántica sobre el arte. Sin embargo, es importante también calibrar el peso que esta identidad pueda tener para el conjunto de la empresa de Kant. Un mismo sentir en la identidad del hombre y la naturaleza pudo haber compartido Kant con sus contemporáneos y haber así, además, abierto el camino para la exaltación romántica. Con todo, su preocupación principal concierne a la legitimidad de los juicios. En esos términos también se expresa Jean-Marie Schaeffer, quien reconoce que con la teoría del genio, Kant abre la puerta a una concepción que girará en torno a la paradoja óntica de la obra de arte: ella es "como si" fuera naturaleza. Según Schaeffer, esta paradoja óntica dará lugar a una teoría especulativa sobre el arte propia del romanticismo y que Kant no comparte (cf. Schaeffer 2000, p. 49). Es más, en su opinión, el análisis del comportamiento estético propuesto en la Crítica de la facultad de juzgar aporta una sustantiva crítica a dicha teoría especulativa (cf. Schaeffer 2000, p. 12). 
p. 272), de apéndices a la empresa medular, pues ¿cómo podríamos apreciar al arte sin conceptos? Ellos están presentes en muchos aspectos de las obras: en las intenciones de los artistas, en el reconocimiento de las obras mismas, en nuestra necesidad de expresarnos sobre ellas y en comunicar a los demás qué encontramos significativo. El arte sin la injerencia de los conceptos es, con toda razón, un oxímoron, un imposible $^{13}$.

La doctrina kantiana del genio debe dar cuenta de este oxímoron. Pero lo hace de una manera sumamente problemática. Su núcleo está en la definición del genio como "el talento (don natural) que da la regla al arte" (Kant 1991, p. 216, § 46). Es mérito de Jean-Marie Schaeffer señalar cuán importante ha sido esta definición para la reflexión sobre el arte en los últimos dos siglos (Schaeffer 2000, p. 40 ss.).

Con respecto a la cuestión del genio es, a mi juicio, importante subrayar que Kant aborda el problema de la creación artística en términos de sus productos ejemplares. Veamos cuál es el núcleo de la argumentación kantiana. En la Analítica de lo bello, Kant nos explica que la cualidad estética concierne a la capacidad para ser afectados de una manera no objetiva sino subjetiva ante una representación. Tal capacidad se expresa en un juicio que sostiene "x es bello" y estipula, entonces, que se trata del caso de una regla bajo la condición -supuesta y a la que apela- de que todos podamos juzgar de la misma manera, es decir, que podamos coincidir en que " $\mathrm{x}$ es bello". Lo peculiar es que la regla misma no puede establecerse objetivamente, pues consiste en la misma facultad de juzgar, el sensus communis, atribuible a cualquier sujeto, y que sustenta por qué somos capaces de reaccionar estéticamente. No hay garantía alguna de que tal sea el caso de la regla, pero en esta lógica sui géneris está concernida la facultad de cada uno o, como sostiene Kant, la capacidad de "ponerse en el lugar de los otros" (Kant 1991, p. 204, § 40). Esta lógica del enjuiciamiento opera también en la de la producción. El artista -o el genio- posee tal sensus communis y con sus creaciones estipula nuevamente como ejemplos que tales objetos, a saber sus obras, son los casos de una regla que concierne a cada uno, esto es, a toda la esfera de los que juzgan. Las obras de arte serían los ejemplos de una regla que todos estamos en condiciones de operar. Así, aun cuando las obras de arte puedan ser tomadas como objetos entre otros en el mundo, sus cualidades estéticas no dependen de condiciones objetivamente perceptibles, cuanto de la posibilidad de que propicien una misma manera de juzgar, de que logren activar una misma capacidad subjetiva de reaccionar, basada en algo que todos, como sujetos, poseemos: el sensus communis.

Hay otros aspectos importantes de la doctrina del genio por considerar. Ella permite sentar una diferencia importante entre la mera "imitación" y la "sucesión", capaz de explicar la originalidad e innovación de las manifestaciones estéticas (cf. Kant 1991, p. 226, § 49). De acuerdo con esa diferencia, muchas obras de arte agotarían su razón de ser en el seguimiento meramente reproductivo y mecánico de ejemplos

13 Kant hace alusión a este punto, especificando que el arte siempre supone la representación de un fin (cf. Kant 1991, p. 216, § 43). 
o de casos de coincidencia estética. La innovación artística, en cambio, parte de la elaboración original e inigualable en el cauce de producciones tomadas también como modelos o ejemplos, pero con respecto a las cuales los artistas ejercen su libertad. En el lenguaje de Kant, serían justamente "genios" quienes fuesen capaces de tal innovación, es decir, aquellos que estuviesen en condiciones de preservar, en la lógica de la autonomía estética, la aptitud y libertad para crear nuevos ejemplos de aquello que deba valer como arte. Estarían pues en condiciones de crear, de descubrir, bajo la pauta de la sucesión y no de la imitación, nuevos casos de una regla no objetivable, aunque se muestre dicha regla a primera vista como un objeto, es decir como una obra a ser tomada como modelo susceptible de una futura reelaboración.

La autonomía estética consistiría así, desde el punto de vista de la creación, en el ejercicio de la facultad de juzgar como la posibilidad de mostrar, en el ejemplo que es la obra de arte, una misma comunidad de sentimiento. Y, desde el punto de vista de la apreciación o enjuiciamiento, también en tal ejercicio como la posibilidad de coincidir, a propósito de la obra en cuestión, en el sentimiento. Con sentimiento no debe, por supuesto, entenderse una emoción privada, particular, sino la misma reacción estética, que Kant no duda en calificar como "sentimiento vital” (Kant 1991, p. 122, § 1). Artistas y público no coincidiríamos por preferencias personales, idiosincrasias o filiaciones, por motivos psicológicos o culturales, sino en virtud de nuestra pertenencia a una comunidad intersubjetiva. En la medida en que tal pertenencia no se sustenta en que de hecho coincidamos, sino que, en la explicación que ofrece Kant, al apreciar o al hacer arte la planteamos, la exigimos, la buscamos, la experiencia estética está abierta a un universo plural, público, de crítica y revisión constantes.

La lectura que propongo sobre la dimensión pública que tiene la estética de Kant discrepa de muchas interpretaciones críticas importantes. Las discrepancias pueden sustentarse de forma más o menos acuciosa en determinados análisis del texto kantiano. En momentos clave, como por ejemplo, cuando se trata de establecer el peso específico que tiene la teoría del arte o de la creación artística frente al análisis del juicio de gusto, los estudiosos sugieren diversas lecturas, ninguna de las cuales puede obviar ni distorsionar la flagrante y obvia intención kantiana de mostrar que solo en la apreciación de la belleza natural tiene lugar la ansiada y plena autonomía estética ${ }^{14}$. Tampoco ha sido mi propósito afirmar lo contrario, simplemente he querido poner de relieve la tesis, por lo demás del propio Kant, que las mismas condiciones que valen para el juicio sobre los productos naturales también son válidas para las creaciones artísticas. Problema que está asociado, pero que es distinto, al de cuándo y cómo se da la plena autonomía estética.

Pero, además, las interpretaciones discrepantes a las que antes he aludido no se refieren tanto a problemas específicos de análisis del texto kantiano, sino a cuán 
pertinente o fructífera es, en conjunto, la estética de Kant para esclarecer las cuestiones que conciernen al arte. Así, desde los inicios de su recepción, en las Lecciones sobre estética de Hegel se alza una voz crítica, continuada en la Teoría estética de Adorno, en la hermeneútica de Gadamer o, más recientemente, en los escritos sobre arte de Danto. En todos los casos, bajo distintos argumentos y con variantes, se hace hincapié, y no sin razón, en que la estética de Kant está centrada en el sujeto que juzga (o, también, que hace arte), y se señalan los peligros que la entronización de la categoría del gusto pueda significar como puerta abierta a la intromisión del subjetivismo y la arbitrariedad. Confío en haber mostrado que esta última objeción -la del subjetivismo y la arbitrariedad- es lo más lejana posible al espíritu que anima a la Crítica de la facultad de juzgar. Es más, buena parte de la estrategia que Kant emplea en el análisis y fundamentación del juicio de gusto se dirige justamente a desterrar toda pretensión que solo exhiba la preferencia personal. La crítica, en cambio, que incide en la preeminencia del sujeto en su estética, es más pertinaz y consecuente, pues está unida a la importante impugnación de que las manifestaciones artísticas mismas, las obras de arte como tales, no le merecen ninguna consideración.

Este último reproche debe tratarse con más cuidado y atención. En efecto, no encontraremos en Kant observaciones tendientes a esclarecer o interpretar determinadas obras de arte. Este interés es muy lejano a la intención manifiesta de su obra. Y, en este punto, el contraste con Hegel no podría ser más evidente y aleccionador. Empeñado este último en escudriñar cómo el "Espíritu" se manifiesta en todos los aspectos de la realidad, tampoco el arte podría quedar ajeno a este ímpetu de lo absoluto. Así, en sus Lecciones es imprescindible la referencia directa a obras y momentos de la historia del arte, es indispensable la clasificación de las artes y el análisis de lo que estos aspectos, encarnados en las obras, significan al interior del movimiento del "Espíritu". Nada más extraño a Kant, cuyo propósito es más bien modesto, aunque audaz: especificar qué es lo estético y fundamentar su validez ${ }^{15}$. Con importantes variaciones, precisiones, críticas y reformulaciones, todos los autores antes mencionados -Adorno, Gadamer y Danto- se reclaman deudores de la tradición inaugurada con Hegel. Para ellos es impensable plantear una estética que no se aboque al estudio de las manifestaciones artísticas en su concreción y determinación.

Insistamos en esta cuestión: mientras que para Kant de lo que se trata es de delimitar con precisión el ámbito y las pretensiones de lo estético, después de él importan ante todo sus contenidos y materiales. A mi entender se trata de dos tareas distintas y no necesariamente incompatibles, siempre que se reconozca que no persiguen lo mismo y que podrían ser, quizá, complementarias. Pasar por alto esa diferencia podría significar intentar explicar la experiencia estética solamente a partir de determinados constituyentes materiales u objetivos. Pero, en tal sentido, la advertencia de Danto -compartida por Kant- es crucial: lo que hace una obra de arte no puede

15 Esta tarea del filósofo trascendental permite, además, especificar el lugar de la crítica de arte en su sentido moderno (cf. Kritik der Urteilskraft, § 34). 
establecerse simplemente por las propiedades observables del objeto. Ciertamente, esas propiedades están allí y no pueden en absoluto obviarse para dar cuenta de nuestra experiencia estética, pero en ésta apelamos principalmente a un ámbito intersubjetivo, difícil de establecer y precisar, pero que nos hace conscientes de una pertenencia más allá de lo objetual y cosificado.

Quisiera concluir observando que el título de este artículo, "La estética de Kant: el arte en el ámbito de lo público", obedecía a un afán polémico y provocador. A juzgar por sus críticos, Kant pareciera ser el autor menos indicado de la tradición para hablar sobre arte. Pero eso sería así, si desconociésemos que lo que intenta es sacar a la luz el ámbito intersubjetivo, esto es, eminentemente público, en el que nuestras opiniones sobre el arte - tanto de quienes lo aprecian como de quienes lo hacenpor derecho y de hecho se insertan. Se hace público, claro está, porque los artistas con sus obras lo plasman y los curadores lo exhiben. Esa es una forma eminente de comunicación. Pero el arte que se apodera de nuestra atención, que nos hace detenernos en él, que, como también dice Kant, da lugar a una actividad reflexiva, nos lleva siempre a comunicarnos directamente con los demás, ya sea vía el oficio de los críticos, o por la simple urgencia de tratar de decirles a otros qué encontramos de imborrable o valioso en él, o incluso en el silencioso encuentro y búsqueda de las ocasiones propicias de obras y artistas que nos importan. Todas estas formas plurales, distintas de comunicación sugieren que coincidimos, aunque no podríamos decir objetivamente en qué. Lo cierto es que ponen al descubierto una dimensión pública, posible de ser atribuida solo a seres humanos que así, al modo estético, se reúnen con otros.

No tendría caso que buscásemos esa concordancia con la secreta o manifiesta intención de imponer nuestro juicio a los demás, como tampoco con la tenue y vana esperanza de que de una u otra forma - por consenso, disuasión o persuasión- ella se corroborase. El modo estético torna valiosa la coincidencia, pero no porque ésta sea obligatoria, forzosa o cuantificable. Todo lo contrario. Significa, más bien, una experiencia gratuita y libre.

Sostuvo Wittgenstein alguna vez que en el arte es difícil decir algo que sea tan bueno como no decir nada (cf. Wittgenstein 1995, p. 63). Entre el mutismo y la charlatanería, el arte nos coloca en la situación de preservar, con cuidado y estima, un modo valioso y peculiar de lo público.

\section{Referencias bibliográficas}

Adorno, T. W. (1989), Teoría estética. Madrid: Taurus.

Allison, Henry E. (2001), Kant's Theory of Taste. Cambridge University Press.

Baeumler, Alfred (1981), Das Irrationalitätsproblem in der Ästhetik und Logik des 18. Jahrhunderts bis zur Kritik der Urteilskraft. Darmstadt: WbG.

Biemel, Walter (1959), Die Bedeutung von Kants Begründung der Ästhetik für die Philosophie der Kunst. Colonia: Universitätsverlag. 
Cabot, Mateu, ed. (1999), Belleza y verdad. Sobre la estética entre la Ilustración y el Romanticismo. Barcelona: Alba.

Danto, Arthur C. (2000), "Prefacio", en Jean-Marie Schaeffer, ed., Art of the Modern Age. Philosophy of Art from Kant to Heidegger. Princeton University Press; pp. ix-xvii.

(1999), Después del fin del arte. Barcelona: Paidós.

(2002), La transfiguración del lugar común. Una filosofía del arte. Barcelona: Paidós.

(2003), Más allá de la caja de Brillo. Madrid: Akal.

Escoubas, Eliane (2004), L'Esthétique. París: Ellipses.

Fistioc, Mihaela C. (2002), The Beautiful Shape of the Good. Platonic and Phytagorean

Themes in Kant's Critique of the Power of Judgement. Nueva York: Routledge.

Franzini, Elio (2000), La estética del siglo XVIII. Madrid: Visor.

Freeland, Cynthia (2003), Pero ¿esto es arte? Madrid: Cátedra.

Früchtl, Josef (1994), "De la comunicabilidad de lo no comunicable", análisis-art. 11: $43-65$.

Gadamer, Hans-Georg (1975), Wahrheit und Methode. Tübingen: J.C.B. Mohr.

Hegel, G. W. F. (1970), Vorlesungen über die Ästhetik, Werke. Frankfurt a.M.: Suhrkamp. 20 vols., vol. 13.

Heintel, Peter (1970), Die Bedeutung der Kritik der ästhetischen Urteilskraft für die Transzendentale Systematik. Bonn: Bouvier.

Hume, David (2003), De la tragedia y otros ensayos sobre el gusto. Buenos Aires: Biblos.

Kant, Immanuel (1968), Kritik der Urteilskraft. Werkausgabe, ed. por W. Weischedel. Frankfurt a.M.: Suhrkamp, 1968. 12 vols., vol. 10.

(1991), Crítica de la facultad de juzgar, traducción de Pablo Oyarzún. Caracas: Monte Ávila.

Lyotard, Jean-François (1988), Leçons sur l'Analytique du sublime. París: Galilée.

Mörchen, Hermann (1930), Die Einbildungskraft bei Kant. Halle: Niemeyer.

Perniola, Mario (2001), La estética del siglo veinte. Madrid: La balsa de la Medusa.

Prego, Charo (1990), "El lugar de la belleza artística en la 'Crítica del Juicio"”, en J. L. Villacañas et al., Estudios sobre la "Crítica del Juicio". Madrid: Visor; pp. 129-146.

Schaeffer, Jean-Marie (2000), Art of the Modern Age. Philosophy of Art from Kant to Heidegger. Princeton University Press.

Villacañas, J. L., Bozal, V., Pérez Carreño, Fca., Trías, E., Prego, Charo y Martínez Marzoa, F. (1990). Estudios sobre la "Crítica del Juicio". Madrid: Visor.

Wittgenstein, Ludwig (1995), Aforismos. Cultura y valor. Madrid: Espasa Calpe. 